\title{
Bisphosphonate Modulates Cementoblast Behavior In Vitro
}

Yong-Hee P. Chun, ${ }^{*}$ Brian L. Foster ${ }^{\dagger}$ Patricia A. Lukasavage, ${ }^{*}$ Janice E. Berry, ${ }^{*}$ Ming Zhao, ${ }^{*}$ Howard C. Tenenbaum, ${ }^{\ddagger}$ and Martha J. Somerman ${ }^{\dagger}$

Background: Cementum formation is deemed to be instrumental for the successful regeneration of periodontal tissues, and thus events and modifiers of cementum formation and mineralization need to be determined. This study aimed to determine whether the bisphosphonate 1-hydroxyethylidene-1, 1-bisphosphonate (HEBP) altered the behavior of immortalized cementoblasts (osteocalcin-cementoblasts [OCCM]).

Methods: OCCM from transgenic mice were exposed to HEBP at concentrations ranging from 0.01 to $10.0 \mu \mathrm{M}$. The assays performed included the count of cell number for proliferation, Northern blot analysis for gene expression (up to 10 days for core binding factor alpha-1 [Cbfa1], bone sialoprotein [BSP], osteocalcin [OCN], and osteopontin [OPN], markers for cementoblast/osteoblast maturation/mineralization), von Kossa stain and alizarin red S stain for mineralization, and enzyme assay ( $p$-nitrophenol phosphate cleavage) for alkaline phosphatase (ALP) activity.

Results: Mineral nodule formation was inhibited at the higher doses of HEBP (1.0 and 10.0 $\mu \mathrm{M})$ only. At early stages (1, 3, and 6 days), gene expression assays revealed only subtle changes in treated cells versus untreated cells, but by day 10 , groups treated with lower doses $(0.01$ and $0.1 \mu M)$ were markedly different at the gene expression level. OCN was significantly downregulated (70\%) at the lowest dose, with less pronounced effects at higher doses. In concurrence, the master switch gene for osteoblasts, Cbfa1, was also downregulated at the lower doses. Inversely, OPN mRNA was enhanced at the lower doses. ALP activity was not altered by HEBP.

Conclusion: Bisphosphonate alters cementoblast function in vitro through the regulation of gene expression and mineral formation. J Periodontol 2005;76:1890-1900.

\section{KEY WORDS}

Bisphosphonate; cementoblasts; drug effects; gene expression; mineralization.

\footnotetext{
* Department of Periodontics/Prevention/Geriatrics, School of Dentistry, University of Michigan, Ann Arbor, MI.

† Department of Periodontics, School of Dentistry, University of Washington, Seattle, WA.

$\ddagger$ Discipline of Periodontology, Faculty of Dentistry, University of Toronto, Toronto, ON.
}

A major challenge of regenerative periodontal procedures is designing therapies that reliably restore periodontal tissues including soft tissue attachment, cementum, and alveolar bone lost to disease. In vitro investigations provide an opportunity to focus on the defining factors and mediators of individual components of the periodontium, such as cementoblasts.

Examples of recognized mediators of bone metabolism include bisphosphonates (BPs). BPs are primarily known as potent inhibitors of bone resorption. ${ }^{1}$ They are commonly prescribed for the prevention and treatment of bone metabolic diseases, including osteoporosis, Paget's disease, and tumor-associated osteolysis. ${ }^{2}$ The antiresorptive property of BPs might also be beneficial in reducing and preventing bone resorption associated with periodontitis. ${ }^{3}$ Initially, the interest in BPs was related to their inhibition of mineralization, attributed to physicochemical phenomena. ${ }^{4}$ At that time, the discovery of their antiresorptive properties offered new therapeutic perspectives. Most recently, anabolic actions of BPs on bone-forming cells have been reported in vivo and in vitro. ${ }^{5-7}$

Structurally, BPs are analogs of pyrophosphate $\left(\mathrm{PP}_{\mathrm{i}}\right)$, which is used as an ingredient in toothpaste to control calculus formation. As derivatives of inorganic phosphate, BP differs from $\mathrm{PP}_{\mathrm{i}}$ by a carbon atom replacing the oxygen atom and creating P-C-P bonds. Their specific properties include the ability to resist enzymatic hydrolysis and a strong affinity to metal ions and calcium, forming 
both soluble and insoluble complexes. The boneseeking feature of BPs may be responsible for impairing mineralization. Once BP is deposited on the bone surface, it is internalized through pinocytosis ${ }^{8}$ and exerts intracellular effects rather than extracellular effects in osteoclasts. ${ }^{9}$ The potency of the molecule is attributed to its lateral group, and the mechanism of action depends on the absence or presence of a nitrogen. The nitrogen-containing bisphosphonates (N-BP) include alendronate, pamidronate, and others. Examples for non-N-BPs are clodronate and etidronate. N-BPs inhibit farnesyl diphosphate synthase, an enzyme of the mevalonate pathway. As a result, the formation of isoprenoid geranylgeranylated pyrophosphates and guanosine 5' -triphosphate (GTP) binding proteins is prevented, ${ }^{10}$ which is necessary for downstream events in signaling of changes in cellular morphological characteristics, integrins, membrane ruffling, trafficking, and apoptosis. ${ }^{11}$ In contrast, the non-N-BPs are metabolized to cytotoxic adenosine $5^{\prime}$-triphosphate (ATP) analogs and are accumulated intracellularly leading to apoptosis. ${ }^{12}$ These two distinctively different mechanisms indicate two pharmacological classes of BP. ${ }^{13}$

Findings from a clinical trial for the treatment of osteoporosis raised the question of the possible anabolic action of BPs in promoting bone formation, ${ }^{14}$ which was further supported by studies reporting a direct effect of BPs on osteoblasts in vitro and in vivo. ${ }^{5-7}$ However, opposing findings on osteoblast behavior in vitro ranging from stimulatory to inhibitory have been reported, most likely related to the cell type, stage of cell development, type of BP, concentration, and duration of treatment. Components of the extracellular matrix (ECM) are markers of cell activity characteristic for mineralizing tissues. Non-collagenous proteins have been implicated in the selective migration and adhesion of cells at the root surface to maintain a homeostasis between breakdown and mineral formation. Interestingly, the proteins that appear to be key regulators of mineralization, osteopontin (OPN), osteocalcin (OCN), and bone sialoprotein (BSP) are reported to be major non-collagenous components of cementum. ${ }^{15,16}$ Other identified non-collagenous proteins in cementum are osteonectin, ${ }^{17}$ fibronectin, ${ }^{18} \gamma$-carboxyglutamic acid, ${ }^{19}$ and alkaline phosphatase (ALP). ${ }^{20}$ Additionally, an upregulation of ALP is associated with matrix maturation, an initial event in osteoblast differentiation, and this is enhanced when BPs are delivered in low dosages (e.g., 1-hydroxyethylidene-1,1-bisphosphonate [HEBP; generic name: etidronate]). $5,6,21$

Currently, the precise mechanism by which BPs control cells involved in the formation of mineralizing tissues is unknown. Based on the evidence that BPs affect osteoblasts, it was of interest to characterize the cementoblastic response to HEBP by cell proliferation, cell viability, cell morphology, formation of mineral nodules, and gene/protein levels for mineral associated genes. The cementoblasts used here are considered a mature cell line.

\section{MATERIALS AND METHODS}

\section{Cementoblast Cell Culture}

Cementoblasts were isolated from a transgenic mouse (osteocalcin T-antigen [OC-TAg]), containing a transgene composed of the SV 40 large T-antigen under the control of the osteocalcin promoter. Therefore, only cells that expressed osteocalcin (OCN) expressed TAg concurrently and were immortalized in vitro. The cell isolation was done on mice 41 days from vaginal plug date, since at this time cementoblasts are known to express high mRNA levels for the mineralization markers BSP and OCN. ${ }^{22}$ The cementoblasts were harvested from the root surfaces avoiding contamination with osteoblasts by diligent dissection of the periodontal ligament (PDL) fibers. ${ }^{23}$ The teeth were digested using collagenase/trypsin, and then the cells, designated OCCM (osteocalcincementoblasts) were placed in culture. To confirm that the cells' phenotype was maintained during culturing, subclones from single cells were analyzed for the expression of cementoblast markers. The selected subclone, 30, expressed high mRNA levels for BSP and OCN. This phenotype was maintained when the cells were cultured. The isolation of the cementoblasts from developed root surfaces and the presence of the cementoblast markers, OCN and BSP, indicate a mature cell stage. Contamination with PDL cells was of minor concern because PDL cells do not express OCN and consequently do not survive repeated passage. ${ }^{22}$ The permission to obtain murine cementoblasts was granted from the University Committee on Use and Care of Animals (UCUCA) of the University of Michigan to ensure the humane treatment and judicious use of animals.

OCCMs were seeded in six-well plates at a density of 1000 cells $/ \mathrm{ml}$ in triplicate. Cells were maintained in Dulbecco's modified Eagle's medium (DMEM)§ supplemented with 10\% fetal bovine serum (FBS), 100 units $/ \mathrm{ml}$ penicillin, and $100 \mu \mathrm{g} / \mathrm{ml}$ streptomycin they reached confluency, designated as day 0. Depending on the assay, cells were cultured in mineralization media defined as $2 \%$ or $5 \%$ FBS, $50 \mu \mathrm{g} / \mathrm{ml}$ ascorbic acid, and $5 \mathrm{mM} \beta$-glycerophosphate. I The ascorbic acid served to facilitate type I collagen (Col I) synthesis 24 and the $\beta$-glycerophosphate served to induce mineral formation. ${ }^{25}$ The test agent,

\footnotetext{
$\S$ Invitrogen, Carlsbad, CA.

IInvitrogen.

II Sigma, St. Louis, MO.
} 
HEBP, \# was supplemented in concentrations of 0.01 , $0.1,1.0$, and $10.0 \mu \mathrm{M}$. Media were changed every other day. All experiments were repeated on three separate occasions.

\section{Proliferation Assay}

To determine the concentration range and to rule out the toxicity of HEBP, proliferation assays were performed at logarithmic concentrations ranging from 0.01 to $10.0 \mu \mathrm{M}$. These concentrations were selected based on in vitro studies with HEBP in osteoblasts. ${ }^{5}$ To determine the cell number, cells were trypsinized and cell counts taken on days $0,1,6$, and 10 using a Coulter counter.

\section{Cell Viability by Trypan Blue Assay}

A trypan blue assay was used to discriminate viable from non-viable cells. This was performed in parallel with the proliferation assays and also with the doseresponse (HEBP doses 0 to $10 \mu \mathrm{M}$ ) and time-course experiments (days 1, 6, and 10). Trypsinized cells were added to $0.4 \%$ trypan blue stain. ** The percentage of non-viable cells was identified by the uptake of dye.

\section{Cell Morphology}

Cell morphology was observed under a light microscope to confirm cell viability and monitor the cell shape. Cell appearance was documented with randomly selected photographs on days $0,1,6$, and 10 .

\section{Mineralization Assays by von Kossa Staining and Alizarin Red S}

The ability to induce mineralization in vitro is one of the hallmark characteristics of cells associated with hard-tissue formation. Two types of mineralization assays were performed: von Kossa staining ${ }^{26}$ for visualization (i.e., qualitative stains for phosphate in mineral nodules) and alizarin red S staining for the quantification of calcium deposition. ${ }^{27}$ Cells were treated with HEBP at concentrations of $0.01,0.1,1.0$, and 10.0 $\mu M$, based on the proliferation results. On days 5 and 8 and at the end of incubation (day 10), cells were fixed in methanol and stained with $\mathrm{AgNO}_{3}$ for the von Kossa assay. For quantifying the calcium content of the mineral nodule formation, identical wells were stained with alizarin red S. For this assessment, cells were fixed with a 1:1 mixture (volume/volume) of $37 \%$ formaldehyde and ethanol for 5 minutes, washed three times with distilled water, and stained for $10 \mathrm{mi}-$ nutes with a $2 \%$ solution of alizarin red $\mathrm{S}$ ( $\mathrm{pH}$ adjusted to 4.2) dissolved in water. Spectrophotometric quantification at $525 \mathrm{~nm}$ was done after alizarin red $\mathrm{S}$ was redissolved.

\section{Gene Expression by Northern Blot Analysis}

To analyze changes in the OCCM phenotype at the mRNA level, Northern blots were performed. The genes of interest associated with mineral-forming cells used in this study were core binding factor alpha-1 (Cbfa1), OCN, BSP, OPN, and Col I. Once confluency was reached, the media were changed to mineralization media with 5\% FBS, and treatment with HEBP was started. RNA was harvested on days $1,3,6$, and 10 according to the procedure of Xie and Rothblum. ${ }^{28}$ Total cellular RNA was isolated using a modified guanidine thiocyanate procedure ${ }^{\dagger \dagger}$ and quantified by a spectrophotometer at $260 \mathrm{~nm}$. RNA was denatured and size fractionated in a $6 \%$ formaldehyde, $1.2 \%$ agarose gel. The fractionated RNA was then transferred onto a nylon membrane f $^{\neq}$ and cross-linked by ultraviolet (UV) irradiation. $\S \S$ Blots were hybridized with random-primed ${ }^{32}$-P radiolabeled probes, $\|\mid\|$ at $68^{\circ} \mathrm{C}$, washed at high stringency, and exposed to film ${ }^{\text {It }}$ at $-70^{\circ} \mathrm{C}$ with intensifying screens for 24 to 72 hours.

The following probes were used: Cbfa1 (a gift from Dr. G. Karsenty, Department of Molecular and Human Genetics, Baylor College of Medicine, Houston, Texas), ${ }^{29}$ BSP (M-BSP consisting of $1 \mathrm{~kb}$ mouse CDNA in PCR II'; a gift from Drs. M. Young and L. Fisher, National Institute of Dental and Craniofacial Research/National Institutes of Health [NIDCR/NIH], Bethesda, MD), ${ }^{30}$ OPN (MOP-3 consisting of $1 \mathrm{~kb}$ mouse OPN cDNA in PCR II ${ }^{37}$; a gift from Drs. $M$. Young and L. Fisher, NIDCR/NIH), ${ }^{31}$ OCN (400 base pairs [bp] of mouse OCN in pSP65; a gift from Dr. J. Wozney, Genetic Institute, Wyeth Ayerst Research, Cambridge, Massachusetts), ${ }^{32}$ and type I collagen (consisting of $1 \mathrm{~kb}$ bovine type I collagen in Bluescript; a gift from Drs. M. Young and L. Fisher, NIDCR/NIH). Hybridized blots were scanned and quantitated. To compensate for differences in loading, the density of specific RNAs were normalized to $18 \mathrm{~S}$ rRNA and expressed as a ratio.

\section{Alkaline Phosphatase Activity Assay}

Alkaline phosphatase is an early marker of differentiation in cells that promote mineral formation and is involved in controlling phosphate metabolism. ALP catalyzes the cleavage of a phosphate group from a variety of compounds, and its activity is measured by its ability to cleave phosphate from $\mathrm{p}$-nitrophenylphosphate (PNPP), a reaction that can be quantitated spectrophotometrically.

Cells were plated at 1,000 cells $/ \mathrm{ml}$ in triplicate. Upon confluence, designated day 0 , media were removed, and cells were incubated in mineralization media containing 5\% FBS and supplemented with 50 $\mu \mathrm{g} / \mathrm{ml}$ ascorbic acid and $5 \mathrm{mM} \beta$-glycerophosphate.

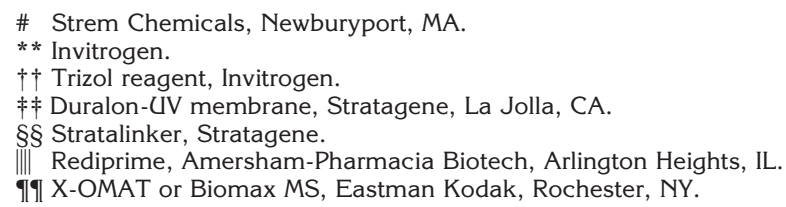


Table I.

\section{Summary of HEBP as Regulator of Cementoblast Function}

\begin{tabular}{|c|c|c|c|c|c|c|c|c|}
\hline $\begin{array}{l}\text { HEBP } \\
\text { Dose }\end{array}$ & $\begin{array}{c}\text { Proliferation, Viability, } \\
\text { and Morphology }\end{array}$ & $\begin{array}{l}\text { Protein } \\
\text { ALP }\end{array}$ & Mineralization & Cbfal & OCN & Col I & BSP & OPN \\
\hline Low* & - & - & - & $\downarrow$ & $\downarrow$ & - & - & $\uparrow$ \\
\hline $\mathrm{High}^{\dagger}$ & - & - & $\downarrow^{\ddagger}$ & - & - & - & - & - \\
\hline
\end{tabular}

* Low doses of HEBP: 0.01 and $0.1 \mu \mathrm{M}$.

$\dagger$ High doses of HEBP: 1.0 and $10.0 \mu \mathrm{M}$.

\# Abolished.

$+=$ expressed; $-=$ no change; $\downarrow$ = decreased; $\uparrow=$ increased.

While experimental wells were treated up to 10 days with mineralization media and HEBP at a concentration of $0.0,0.01,0.1,1.0$, and $10.0 \mu \mathrm{M}$, the control well received 10\% FBS, DMEM, and antibiotics but without ascorbic acid or $\beta$-glycerophosphate. Media and HEBP were changed every other day. On day 5 and at the end of incubation on day 10, alkaline phosphatase activity was determined. Cells were washed with phosphate buffered saline (PBS), removed into $2 \mathrm{mM}$ phenylmethlysulfonyl fluoride (PMSF), and sonicated. Cell lysates were centrifuged for 20 minutes at $1500 \times \mathrm{g}$, and the supernatants were used for the enzyme assay described above. The experiments were carried out three times.

\section{Statistical Analysis}

All experiments were carried out three times, on separate occasions, with similar results. Results were compared using the mean $\pm \mathrm{SD}$. For statistical analysis, one-way analysis of variance (ANOVA) and Tukey-Kramer multiple comparison tests were performed. ${ }^{\# * * *}$

\section{RESULTS}

Table 1 summarizes the results discussed below. The cementoblast response depended highly on the dose of HEBP treatment: low doses $(0.01$ and $0.1 \mu \mathrm{M})$ versus high doses $(1.0$ and $10.0 \mu M)$. In brief, at the higher doses, the cementoblast phenotype was not altered, but mineral formation was blocked. The abrogation of mineralization was most likely attributed to physicochemical phenomena. In contrast, at the lower doses, the most evident finding was a modulation of gene expression. Cbfa 1 and OCN mRNA levels were downregulated, whereas OPN mRNA was increased. Mineral formation was observed in controls, and this effect was not altered by low doses of HEBP. Similarly, HEBP did not induce alkaline phosphatase activity in cementoblasts.

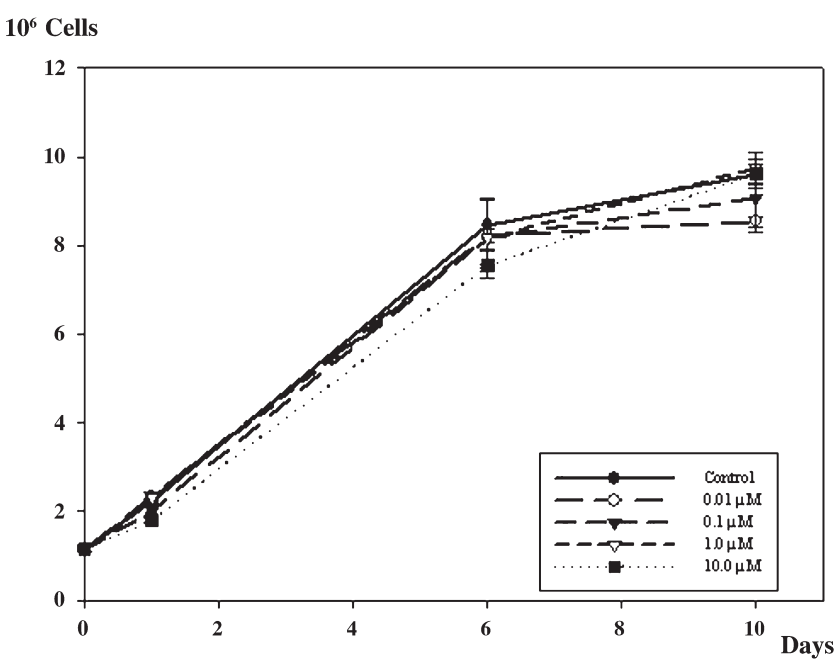

Figure I.

Effect of HEBP on proliferation. Cementoblasts were cultured in media with $2 \%$ FBS and ascorbic acid with or without HEBP.

\section{Effect of HEBP on OCCM Proliferation (Fig. 1)}

Proliferation assays were analyzed using a Coulter counter to determine the dose-dependent effects of HEBP on OCCMs. As shown in Figure 1, similar proliferation rates were obtained for HEBP-treated cells at all doses versus untreated cells throughout the entire 10-day experimental phase. Cells grew in logarithmic phase up to day 6 and then reached a plateau phase with confluence.

\section{Effect of HEBP on Cell Viability (Fig. 2)}

Reports of cell death induced by BPs prompted us to determine cell viability, using trypan blue staining. Approximately $8 \%$ to $14 \%$ cell death is noted at all time points, independent of HEBP treatment. At day

\#\# Excel 9.0, Microsoft, Redmond, WA.

*** GraphPad InStat 3.0, GraphPad Software, San Diego, CA. 


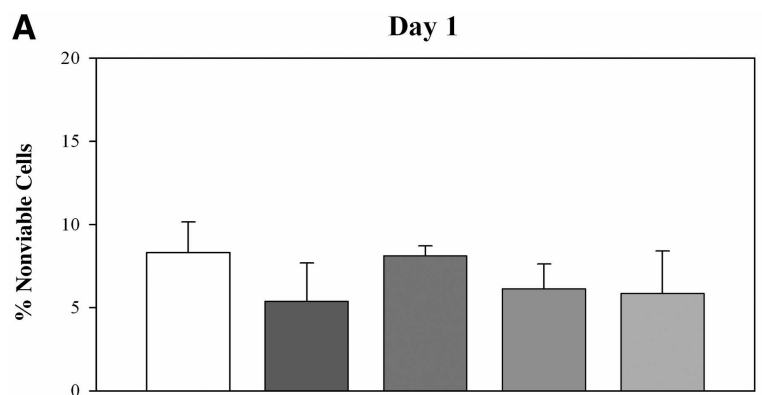

B

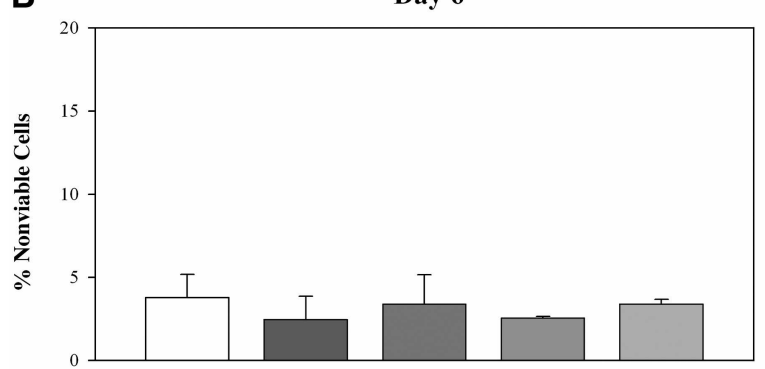

C

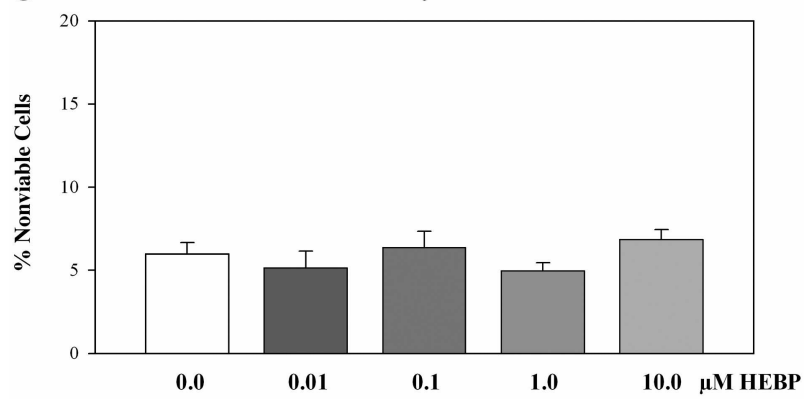

Figure 2.

Effect of HEBP on cell viability. Trypan blue exclusion assay was performed in parallel to proliferation assay. The assay, done three times, showed no difference in OCCM viability following HEBP treatment versus untreated controls (A, day I; B, day 6; and $\mathbf{C}$, day 10).

6 , the average of non-viable cells decreased to $<4 \%$. An increase in cell death was noted from days 6 to 10 , most likely related to overconfluency (see Fig. 1 ; plateau effect), and thus a certain percentage of cells were unable to adhere and survive. HEBP-treated cells at all doses exhibited the same pattern as treated cells (Fig. 2).

\section{Effect of HEBP on Cell Morphology (Fig. 3)}

Changes in cell morphology are one indication of changes in cell phenotype. Here, cell morphology appeared to be minimally affected by HEBP treatment at all four doses up to 10 days when compared to the control (Fig. 3). A slightly more cuboidal versus fibroblastic appearance was suggested at day 6 at $10 \mu \mathrm{M}$ and at day 10, at the highest doses of HEBP, at 1 and $10 \mu \mathrm{M}$.

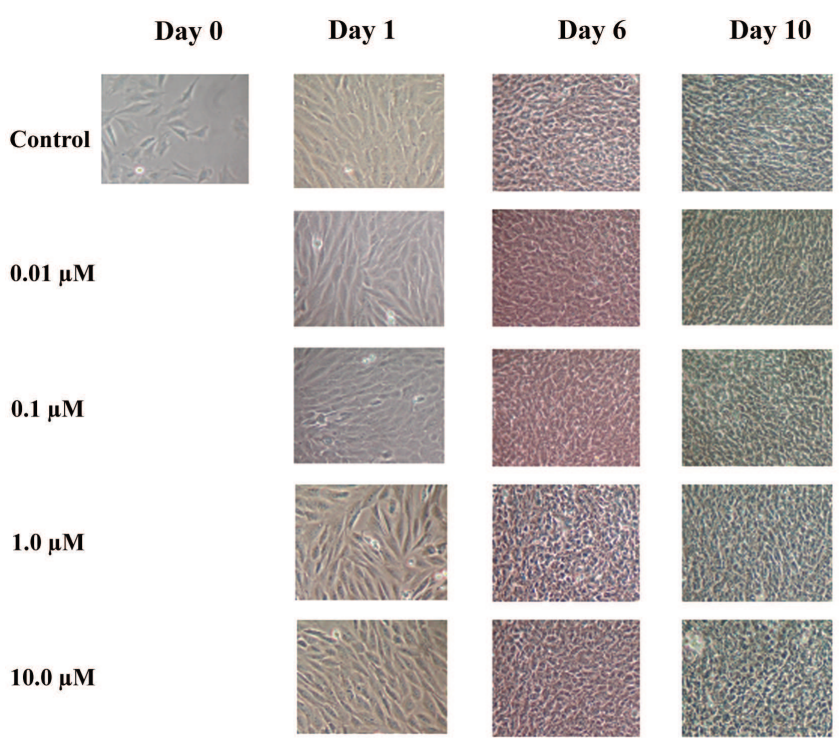

Figure 3.

Effect of HEBP on cell morphology. Cell morphology was observed under a light microscope after exposure to $\operatorname{HEBP}(0.01$, 0.1, 1.0, and $10.0 \mu \mathrm{M})$ up to 10 days.

\section{Effect of HEBP on Mineralization (Fig. 4)}

Mineralization was evaluated from days 5 to 10 to determine whether or not HEBP would promote or inhibit mineralization. As expected, neither untreated nor BP-treated cells mineralized at day 5 . In accordance with previous data, OCCM formed mineral nodules after 8 days, as visualized by von Kossa staining and quantified by alizarin red $S$ staining (Fig. 4). At doses of 0.01 and $0.1 \mu \mathrm{M}$, HEBP mineralization was undisturbed, while at high doses (1.0 and $10.0 \mu \mathrm{M})$, mineralization was completely suppressed. A longer exposure time to HEBP (10 days) did not lead to further differences in mineralization versus those seen at day 8.

\section{Effect of HEBP on Gene Expression (Fig. 5)}

Expression of genes associated with cementoblast maturation is a useful tool to assess changes in phenotype. Key markers for mineral associated proteins in bone, which are valid for cementum, include Cbfa1, BSP, OCN, and OPN. No noticeable modification in expression of the genes of interest was noted in cells treated with HEPB for 1,3 , and 6 days regardless of the HEBP concentration (data not shown). However, at day 10, distinct changes in OCCM gene expression were noted in cells exposed to HEBP versus untreated control cells (Fig. 5). The master-switch gene for osteoblasts, Cbfa1, was downregulated at low doses (0.01 and $0.1 \mu \mathrm{M})$ of HEBP, while no noticeable alterations were seen at high doses (1.0 and 10.0 $\mu \mathrm{M})$, compared to $2 \%$ FBS controls. Interestingly, this 

$\mu \mathrm{MCa}^{2+}$
5 Days
8 Days
10 Days

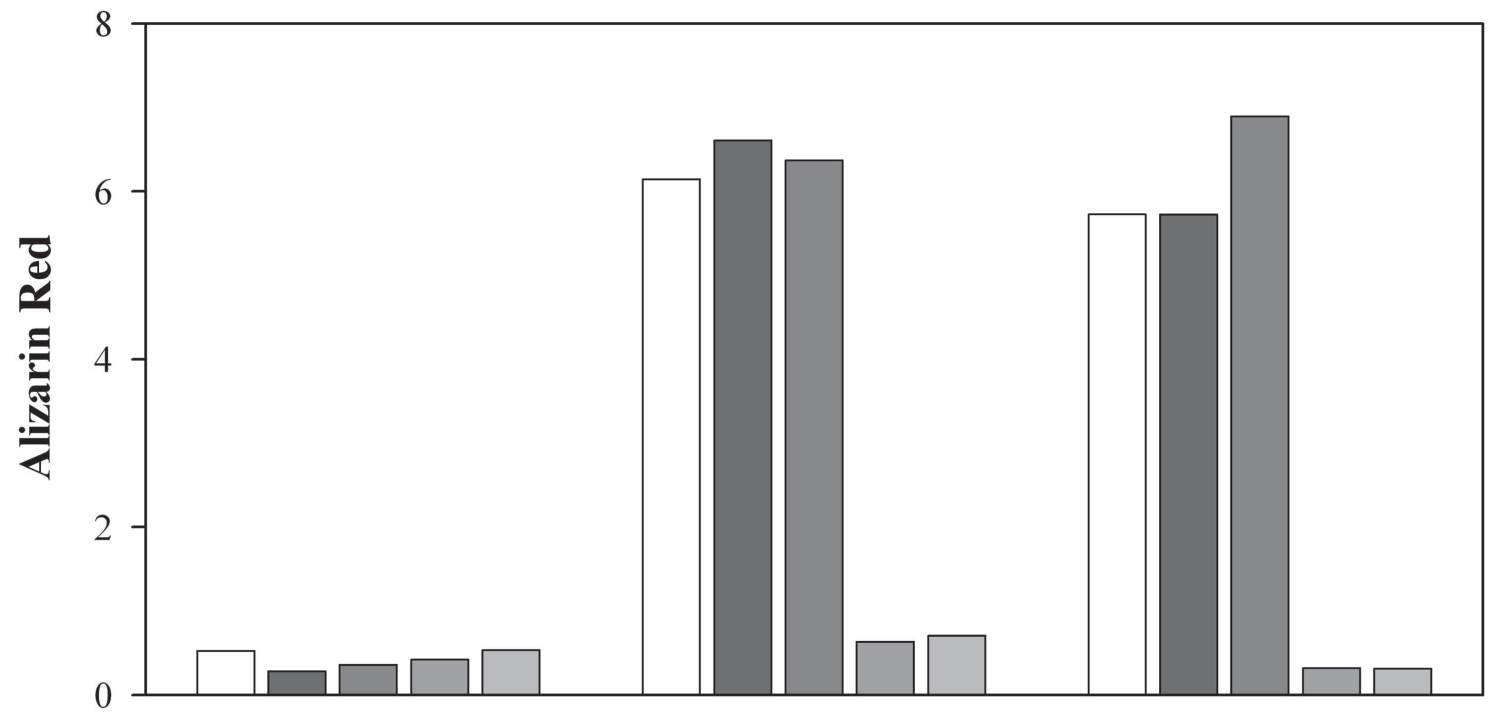

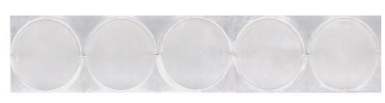

$\begin{array}{lllll}0.0 & 0.01 & 0.1 & 1.0 & 10.0\end{array}$

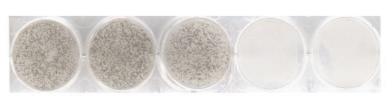

$\begin{array}{llllll}0.0 & 0.01 & 0.1 & 1.0 & 10.0\end{array}$

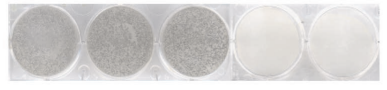

$\begin{array}{lllllll}0.0 & 0.01 & 0.1 & 1.0 & 10.0 & \mu M & \text { НEBP }\end{array}$

Figure 4.

Effect of HEBP on mineralization. von Kossa staining served to visualize mineralization, whereas alizarin red S was used for quantification. In previous studies, OCCMs were shown to be capable of promoting mineral formation within 8 days in vitro. OCCMs were cultured in mineralization media and HEBP $(0.01$ to $10.0 \mu \mathrm{M})$.

contrast was found to be even more pronounced in OCN mRNA levels relative to $2 \%$ FBS controls, a gene known to be very responsive to Cbfa1. Conversely, OPN mRNA levels were upregulated at low doses of HEBP, whereas at high doses OPN, mRNA levels remained comparable to the $2 \%$ FBS controls. BSP gene expression remained fairly constant and similar to untreated cells, regardless of the HEBP concentration used.

\section{DISCUSSION}

Cementum, for the most part, is relatively inert, and resorption in this part of the periodontium is not part of physiologic metabolism but is usually related to inflammation or trauma. Following an insult to the cementum, cementoblasts and/or cells within the local environment have the capacity to repair lost tissues. ${ }^{33}$ This study was designed to investigate the effect of HEBP on the behavior of cementoblasts in vitro to determine whether or not BPs have potential for use in promoting periodontal regeneration.

Pyrophosphate as well as BP inhibit hydroxyapatite crystal growth successfully and have anticalculus properties. ${ }^{34-36}$ However, pyrophosphate in toothpaste is not delivered in a dose high enough to alter cellular metabolism in the periodontium.

Both agents differ structurally and consequently in their hydrolytic stability with respect to the actions of pyrophosphatase and alkaline phosphatase: BPs are resistant to both enzymes, while $\mathrm{PP}_{\mathrm{i}}$ is hydrolyzed by these enzymes. Therefore, retention on hydroxyapatite surfaces is very long for BPs, but very short for $\mathrm{PP}_{\mathrm{i}}$. In relation to this, BPs interfere with mineralization in a definitive manner since they are hydrolytically stable, while pyrophosphate is hydrolytically unstable and is degraded in the oral cavity. ${ }^{34}$ However, of paramount importance is the concentrationdependent critical level to inhibit mineralization of each agent. As shown in our study, HEBP concentrations of 10 and $1 \mu M$ inhibited mineralization, whereas concentrations of 0.1 and $0.01 \mu \mathrm{M}$ were not inhibitory. Damage to mature tooth mineral has not been reported for pyrophosphates, and for HEBP, minor calcium was released from enamel using an in vitro system, but at a HEBP concentration $10^{6}$ times higher than in our experiments. ${ }^{36}$ 
A

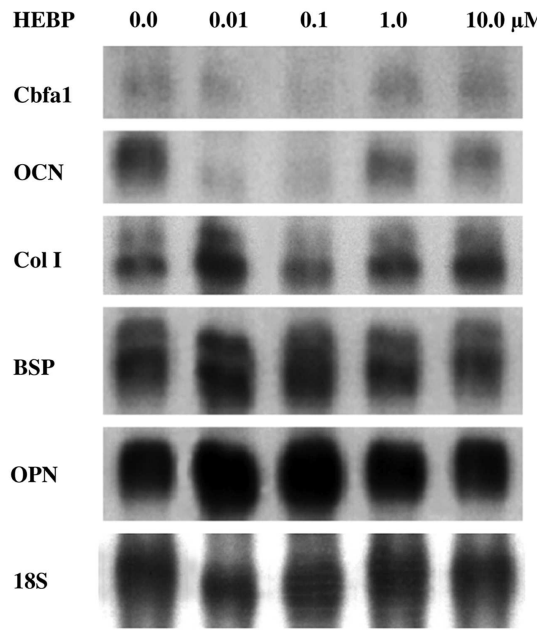

\section{B}

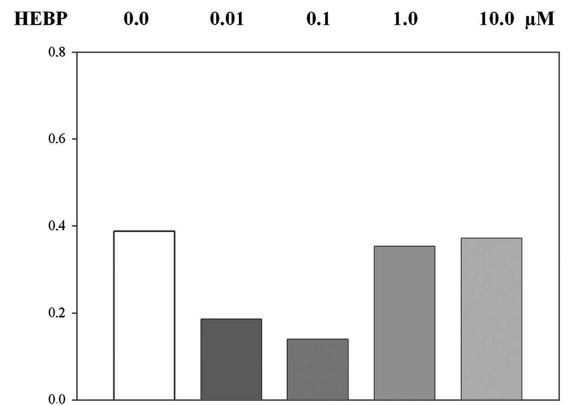

Cbaf1/18S mRNA

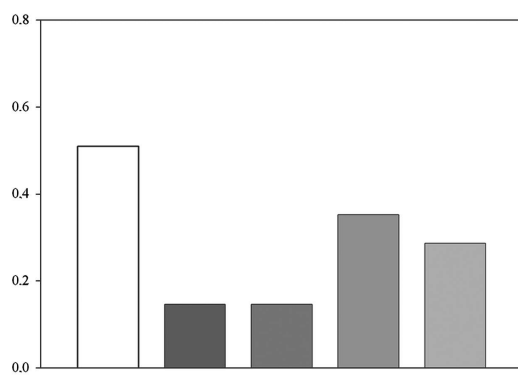

OCN/18S mRNA

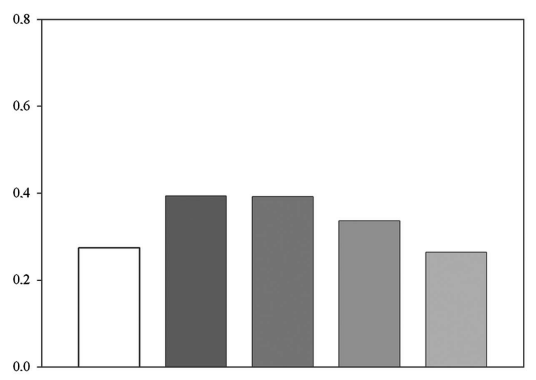

OPN/18S mRNA

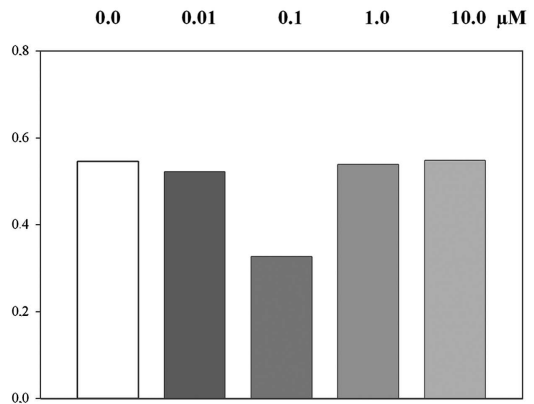

Col I/18S mRNA

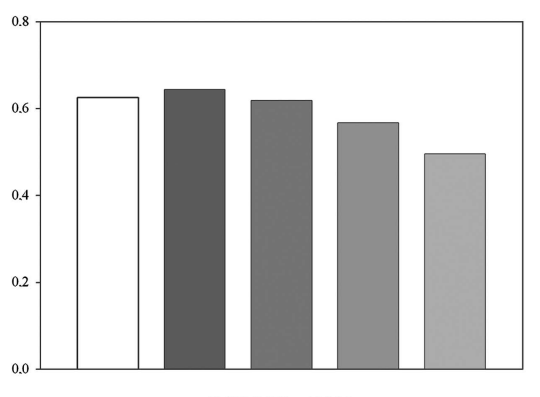

BSP/18S mRNA

\section{Figure 5.}

A) The expression of mineral-associated genes were examined: Cbfa l, OCN, Col I, BSP, and OPN. OCCMs were cultured in mineralization media and HEBP $(0.01$ to $10.0 \mu \mathrm{M})$. The total RNA was extracted from cells after 10 days of treatment and the expression of transcripts was determined by Northern blot analysis. The blots are representative results from one experiment, with similar results in all three experiments. The housekeeping gene I 8S ribosomal RNA serves as an endogenous control. B) Results were normalized with I 8S rRNA and are displayed with bar graphs. After normalization to 18S, distinct differences were noted between BP-treated OCCM-30 and untreated OCCM-30, and these varied depending on the dose delivered.

Bisphosphonates are clinically relevant as antiosteoporosis and anticancer medications. The BP used here, HEBP, ${ }^{\dagger \dagger}$ is a first generation BP used initially for the treatment of Paget's disease and hypercalcemia of malignancy and belongs to the class of $\mathrm{N}$-BPs. For treatment of osteoporosis, the non-N-BP alendronate is classically used, whereas for the treatment of bone metastases, the latest generations of $\mathrm{N}$-BPs (pamidronate, zoledronic acid, and ibadronate) are now used. These newly developed $N$-BPs are up to 20,000 times more potent than HEBP with respect to their ability to inhibit osteoclast function and differ from HEBP in their mechanistic action leading to apoptosis. However, they have about the same ability to inhibit mineralization as HEBP on a mole for mole basis, but inasmuch as they are administered in a much lower dose than HEBP for inhibition of osteoclast activity, their effects on mineralization are minimal.

The results shown here indicate that HEBP did not alter cementoblast proliferation, viability, and morphological characteristics. This is in contrast to reports indicating an increase in osteoblast and preosteoblast proliferation ${ }^{5,7}$ and cell viability ${ }^{37}$ at comparable HEBP concentrations. The ability to promote mineral formation in cementoblasts revealed two clear responses to HEBP exposure: either miner-

$\dagger \dagger \dagger$ Didronel, Procter \& Gamble Pharmaceuticals, Cincinnati, OH. 
alization was abolished at high doses $(1.0 \mu \mathrm{M}$ and $10.0 \mu \mathrm{M}$ ) or mineralization equal to the control occurred at lower doses $(0.01 \mu \mathrm{M}$ and $0.1 \mu \mathrm{M})$. As cementoblasts and osteoblasts are thought to have a similar origin, it is interesting to note that cementoblast behavior in our study diverged in some aspects from osteoblast behavior in the literature. The unchanged level of mineralization in cementoblasts at lower doses was not expected, because a number of previous studies showed that HEBP at comparable doses increases mineral formation in cultured osteoblasts. ${ }^{5,7,21}$ The lack of mineralization associated with BPs manifests clinically as osteomalacia. The high affinity of BPs to apatite results in physicochemical blocking of mineralization at a high concentration of BPs in vitro and in clinic. ${ }^{38,39}$ Analysis of crystals by electron microscope (EM) is one way of evaluating biomineralization, and in previous studies with cementoblasts, using EM analysis in vitro and a severe combined immunodeficiency (SCID) mouse model in vivo, we have shown that the positive stain, in vitro, correlated with biomineralization. ${ }^{23}$ Biomineralization involves many aspects, including the formation and orientation of crystalline materials and the composition of extracellular matrix proteins. Therefore, the analysis of genes associated with mineral formation may provide further clues for the initiation and promotion of biomineralization. However, in our study, none of the changes in gene expression were clearly related to changes in mineralizing activity. Only low doses of HEBP induced changes at the mRNA level in a dose-dependent fashion. The parallel downregulation of Cbfa 1 mRNA and OCN mRNA is remarkable, since Cbfa1, as a transcription factor for osteoblast/cementoblast differentiation, is closely connected to the regulation of OCN expression. ${ }^{40}$

It is significant to our findings that Cbfa1 exhibits opposite functions in immature and mature osteoblasts. ${ }^{41}$ In immature cells, it positively regulates osteoblast differentiation, but at late stages of cell development, it does not seem to be important. In our study, the mineral matrix might have been already developed by mature cementoblasts. Mineralization occurs and is not pronounced as reported in OCN deficient mice $^{42}$ with decreased crystal size/perfection. ${ }^{43}$ It is speculative that physicochemical events are superimposed, since mineral formation depends on many factors, and that a delicate balance of several genes/ECM proteins is crucial for mineralization of root cementum.

Interestingly, both cementoblasts ${ }^{44}$ and osteoblasts respond to inorganic phosphate with an increase in OPN at the mRNA and protein level. ${ }^{45,46}$ Phosphate enters the cell through a Na-dependent phosphate transporter. Whether or not HEBP could serve as a phosphate source is still not clear, but it would help to explain the OPN mRNA upregulation in our experiments. Phosphate seems to play a prominent role in cementum metabolism. Individuals with the genetic predisposition to low levels of tissue non-specific ALP (TNSALP) exhibit severely reduced or the lack of cementum formation and subsequently the loss of teeth at an early age. ${ }^{47}$ Conversely, more recent data shows that mice having mutations in genes that regulate pyrophosphate in the local environment (e.g., the multipass transmembrane protein or ankylosis protein [ANK] and plasma cell membrane glycoprotein-1[PC-1]), resulting in decreased levels of extracellular $\mathrm{PP}_{\mathrm{i}}$, exhibit a phenotype with increased cementum formation. ${ }^{44}$ Osteoblasts and cementoblasts ${ }^{44}$ of these mice in vitro and osteoblasts in vivo were characterized by reduced OPN mRNA and protein levels. Further, OPN ablation increased the mineral content and mineral crystallinity in transgenic

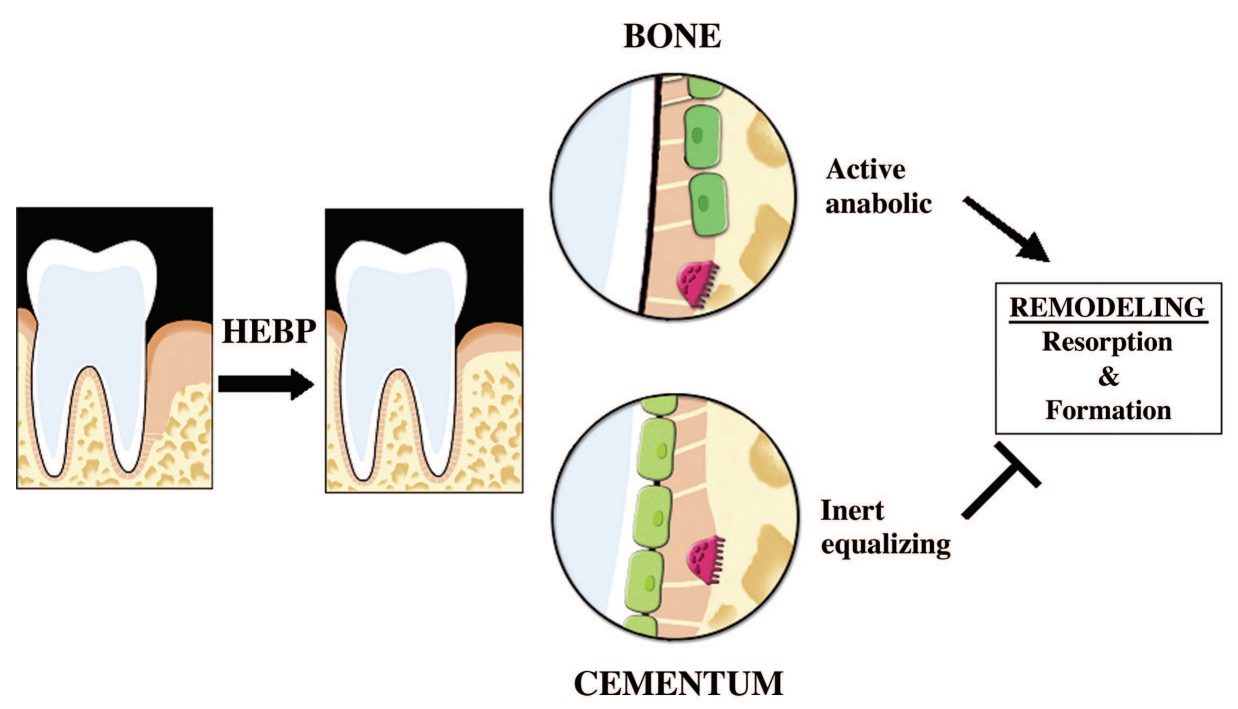

Figure 6.

Hypothetical model for the action of HEBP on the bone and cementum of the periodontium. HEBP may activate bone remodeling by stimulating osteoclast activation, followed by formation and ultimately leading to the reduction of the osseous defect and narrowing of the periodontal ligament. In contrast, cementum has limited remodeling activity and thus may be relatively inert to HEBP; i.e., cementoblasts may play a critical role in protecting the root surface from osteoclast-mediated bone resorption. 
mice. ${ }^{48}$ Thus, it is evident that exposure of osteoblasts and cementoblasts to phosphate and pyrophosphate alters expression of OPN, but the significance of this effect is still not clear. As an early bone marker, ALP is present on the osteoblast cell surface and inside of matrix vesicles released by mineral-forming cells. Existing data indicates that HEBP inhibits ALP by complexing with $\mathrm{Zn}^{2+}$ in the active center of the enzyme, ${ }^{49}$ thereby inhibiting the breakdown of organic phosphates and mineralization. ${ }^{50}$ Increased ALP activity was noted in an osteogenesis model following HEBP treatment, ${ }^{5}$ but in our study with cementoblasts, this was not confirmed (data not shown). In agreement with others, ALP levels appeared to be very low in cementoblasts. ${ }^{51}$ In general, differences in results can be attributed to several factors including dissimilarities in cell type, stage of maturation, duration, and dose of treatment, origin of cells, and assay used. In any event, these findings, while very speculative at this point, support the notion that cementoblasts are quite different from osteoblasts in some respects. It appears that under in vitro conditions the cells used for our studies may be less sensitive than osteoblasts to the physicochemical properties of HEBP at low concentration.

Following an insult to the cementum, cementoblasts and/or cells within the local environment have the capacity to repair lost tissues. ${ }^{33}$ Indeed, it might be that cementum, despite its similarities to bone, is different enough as to protect root surfaces from remodeling, thus controlling ankylosis and resorption (Fig. 6). This would be consistent with the notable differences between HEBP-mediated effects on cementoblasts as compared to osteoblasts. Our in vitro data revealed that cementoblasts respond quite distinctly to HEBP treatment. In comparison to animal studies following HEBP, the doses typically used in mice, $\geq 8 \mathrm{mg}$ phosphorus/kg body weight/day, are higher in concentration compared to in vitro studies. This high concentration was intentionally chosen to inhibit cementum mineralization and to study the periodontal attachment. ${ }^{52}$ However, at lower doses of HEBP ( $\leq 6 \mathrm{mg}$ phosphorus/kg body weight/day), acellular cementum was formed. ${ }^{52}$ Cell-containing tissues in mice, bone, ${ }^{53}$ and cellular cementum ${ }^{54}$ seemed to respond distinctly to daily subcutaneous HEBP injections of $15 \mathrm{mg} / \mathrm{kg}$ body weight ${ }^{53}$ or 10 $\mathrm{mg} / \mathrm{kg}$ body weight. ${ }^{54}$ The PDL width appeared to narrow as a consequence of the formation of alveolar bone, ${ }^{53}$ at times to the point of ankylosis. ${ }^{54}$ Further, the cellular cementum at the apex was bulged out. ${ }^{54}$ Nevertheless, these reported studies did not determine the thickness of cementum histomorphometrically.

In bone remodeling, anabolic and catabolic actions are coupled. In cementum, resorption does not occur under physiological circumstances, and only after marked trauma to cementoblasts. It has been suggested that cementum/cementoblasts have a less responsive metabolism when compared to bone/ osteoblasts. The details of interaction are unknown, but osteoclastic activity seems to relate to the status of cementoblasts in terms of injury versus recovery. ${ }^{55,56}$ Interestingly, the antiresorptive property of HEBP proved beneficial as it limited the amount of root resorption in a mouse model. ${ }^{57}$ Moreover, cementoblasts are claimed to posses an invasion protective function against osteoclast/cementoclast. Once cementoblasts are removed, resorptive cells are unable to differentiate between cementum and bone and induce root and bone resorptions. In our study, cementoblasts demonstrated low responsiveness to a potent stimulus (HEBP) for osteoblasts (Table 1; Fig. 5). Neither anabolic nor catabolic events were induced directly, as measured by proliferation, gene and protein expression supportive for ECM formation, and mineralization. Overall, the differences in the response of osteoblasts versus cementoblasts to HEBP support the concept that cementoblasts contribute to periodontal homeostasis. Caution must be taken with this interpretation because the present study lacks a direct comparison of cementoblast and osteoblast cell lines from the same animal and does not include validating in vivo studies. Future studies including examining other genes and earlier time points along with parallel animal studies would be of value to clarify direct/indirect effects and to determine the value of using bisphosphonates in the treatment of diseases of the periodontium.

\section{ACKNOWLEDGMENTS}

The authors thank Ms. Chen Chen, University of Michigan, for her excellent technical assistance. This study was supported by the National Institute of Dental and Craniofacial Research/National Institutes of Health (DE 09532 to MJS).

\section{REFERENCES}

1. Harada S, Rodan GA. Control of osteoblast function and regulation of bone mass. Nature 2003;423:349. 355.

2. Fleisch H. Bisphosphonates in Bone Disease. San Diego: Academic Press; 2000.

3. Reddy MS, Weatherford TW, Smith CA, West BD, Jeffcoat MK, Jacks TM. Alendronate treatment of naturally-occurring periodontitis in beagle dogs. J Periodontol 1995;66:211-217.

4. Fleisch H, Russell RGG, Francis MD. Diphosphates inhibit hydroxyapatite dissolution in vitro and bone resorption in tissue culture and in vivo. Science 1969; 165:1262-1264.

5. Goziotis A, Sukhu B, Torontali $M$, Dowhaniuk $M$, Tenenbaum HC. Effects of bisphosphonates ADP and 
HEBP on bone metabolism in vitro. Bone 1995;16: 317S-327S

6. D'Aoust P, McCulloch CAG, Tenenbaum HC, Lekic PC. Etidronate (HEBP) promotes osteoblast differentiation and wound closure in rat calvaria. Cell Tissue Res 2000;302:353-363.

7. Giuliani N, Pedrazzoni M, Negri G, Passeri G, Impicciatore M, Girasole G. Bisphosphonates stimulate formation of osteoblast precursors and mineralized nodules in murine and human bone marrow cultures in vitro and promote early osteoblastogenesis in young and aged mice in vitro. Bone 1998;22:455-461.

8. Rogers MJ, Watts DJ, Russell RGG, et al. Inhibitory effects of bisphosphonates on growth of amoebae of the cellular slime mold Dictyostelium discoideum. $J$ Bone Miner Res 1994;9:1029-1039.

9. Sato M, Grasser W, Endo N, et al. Bisphosphonate action. Alendronate localization in rat bone and effects on osteoclast ultrastructure. J Clin Invest 1991;88: 2095-2105.

10. Fisher JE, Rogers MJ, Halasy JM, et al. Alendronate mechanism of action: Geranylgeraniol, an intermediate in the mevalonate pathway, prevents inhibition of osteoclast formation, bone resorption, and kinase activation in vitro. Proc Natl Acad Sci USA 1999;96: 133-138.

11. Benford HL, McGowan NWA, Helfrich MH, Nuttall ME, Rogers MJ. Visualization of bisphosphonate-induced caspase-3 activity in apoptotic osteoclasts in vitro. Bone 2001;28:465-473.

12. Frith JC, Mönkkönen J, Blackburn GM, Russell RGG, Rogers MJ. Clodronate and liposome-encapsulated clodronate are metabolized to a toxic ATP analog, adenosine 5'-(beta, gamma-dichloromethylene) triphosphate, by mammalian cells in vitro. J Bone Miner Res 1997;12:1358-1367.

13. Benford HL, Frith JC, Auriola S, Mönkkönen J, Rogers $M$. Farnesol and geranylgeraniol prevent activation of caspases by aminobisphosphonates: Biochemical evidence for two distinct pharmacological classes of bisphosphonate drug. Mol Pharmacol 1999;56:131-140.

14. Chavassieux PM, Arlot ME, Reda C, Wei L, Yates AJ, Meunier PJ. Histomorphometric assessment of the long-term effects of alendronate on bone quality and remodeling in patients with osteoporosis. J Clin Invest 1997; 100:1475-1480.

15. MacNeil RL, Berry J, Strayhorn C, Somerman MJ. Expression of bone sialoprotein mRNA by cells lining the mouse tooth root during cementogenesis. Arch Oral Biol 1996;41:827-835.

16. MacNeil RL, Berry JE, D'Errico J, Strayhorn C, Somerman MJ. Localization and expression of osteopontin in mineralized and nonmineralized tissues of the periodontium. Ann N Y Acad Sci 1995;760:166-176.

17. Takano-Yamamoto $\mathrm{T}$, Takemura $\mathrm{T}$, Kitamura $\mathrm{Y}$, Nomura S. Site-specific expression of mRNAs for osteonectin, osteocalcin, and osteopontin revealed by in situ hybridization in rat periodontal ligament during physiological tooth movement. J Histochem Cytochem 1994;42:885-896.

18. Somerman MJ, Sauk JJ, Foster RA, Norris K, Dickerson K, Argraves WS. Cell attachment activity of cementum: Bone sialoprotein II identified in cementum. J Periodontal Res 1991;26:10-16.

19. Glimcher MJ, Lefteriou B, Kossiva D. Identification of $\mathrm{O}$-phosphoserine, O-phosphothreonine and g-carboxyglutamic acid in the non-collagenous proteins of bovine cementum; comparison with dentin, enamel and bone. Calcif Tissue Int 1979;28:83-86.

20. Grzesik WJ, Kuzentsov SA, Uzawa K, Mankani M, Robey PG, Yamauchi M Normal human cementumderived cells: Isolation, clonal expansion, and in vitro and in vivo characterization. $J$ Bone Miner Res 1998; 13:1547-1554.

21. Tenenbaum HC, Torontali M, Sukhu B. Effects of bisphosphonates and inorganic pyrophosphate on osteogenesis in vitro. Bone 1992;13:249-255.

22. D'Errico JA, MacNeil RL, Takata T, Berry J, Strayhorn C, Somerman MJ. Expression of bone associated with markers by tooth root lining cells, in situ and in vitro. Bone 1997;20:117-126.

23. D'Errico JA, Berry JE, Ouyang H, Strayhorn CL, Windle JJ, Somerman MJ. Employing a transgenic animal model to obtain cementoblasts in vitro. $J$ Periodontol 2000;71:63-72.

24. Franceschi RT, Iyer BS, Chi Y. Effects of ascorbic acid on collagen matrix formation and osteoblast differentiation in murine MC3T3-E1 cells. J Bone Miner Res 1994;9:843-854.

25. Tenenbaum HC, Heersche JNM. Differentiation of osteoblasts and formation of mineralized bone in vitro. Calcif Tissue Int 1982;34:76-79.

26. Puchtler H, Meloan SN. Demonstration of phosphates in calcium deposits: A modification of von Kossa's reaction. Histochemistry 1978;56:177-185.

27. Puchtler H, Meloan SN, Terry MS. On the history and mechanism of alizarin red and alizarin red $S$ stains for calcium. J Histochem Cytochem 1969;17:110-124.

28. Xie WQ, Rothblum LI. Rapid, small-scale RNA isolation from tissue culture cells. Biotechniques 1991; 11:324-327.

29. Ducy P, Zhang R, Geoffroy V, Ridall AL, Karsenty G. Osf2/Cbfa1: A transcriptional activator of osteoblast differentiation. Cell 1997;89:747-754.

30. Young MF, Ibaraki K, Kerr JM, Lyu MS, Kozak CA. Murine bone sialoprotein (BSP): cDNA cloning, mRNA expression, and genetic mapping. Mamm Genome 1994;5:108-111.

31. Young MF, Kerr JM, Termine JD, et al. cDNA cloning, mRNA distribution and heterogeneity, chromosomal location, and RFLP analysis of human osteopontin (OPN). Genomics 1990;7:491-502.

32. Celeste AJ, Rosen V, Buecker JL, Kriz R, Wang EA, Wozney JM. Isolation of the human gene for bone gla protein utilizing mouse and rat cDNA clones. EMBO J 1986;5:1885-1890.

33. Lindskog S, Blomlöf L, Hammarström L. Cellular colonization of denuded root surfaces in vivo: Cell morphology in dentin resorption and cementum repair. J Clin Periodontol 1987;14:390-395.

34. Jin Y, Yip H- K. Supragingival calculus: Formation and control. Crit Reu Oral Biol Med 2002;13:426-441.

35. Sikder $M N$, Itoh $M$, Iwatsuki $N$, Shinoda H. Inhibitory effect of a novel bisphosphonate, TRK-530, on dental calculus formation in rats. J Periodontol 2004;75: 537-545.

36. Francis MD, Slough CL, Briner WW, Oertel RP. An in vitro and in vivo investigation of mellitate and ethane1-hydroxy-1,1-diphosphonate in calcium phosphate systems. Calcif Tissue Res 1977;23:53-60.

37. Plotkin LI, Weinstein RS, Parfitt AM, Roberson PK, Manolagas SC, Bellido T. Prevention of osteocyte and osteoblast apoptosis by bisphosphonates and calcitonin. J Clin Invest 1999;104:1363-1374. 
38. Francis MD, Russell RGG, Fleisch H. Diphosphates inhibit formation of calcium phosphate crystals in vitro and pathological calcification in vivo. Science 1969; 165:1264-1266.

39. Khairi MR, Altman RD, DeRosa GP, Zimmermann J, Schenk RK, Johnston CC. Sodium etidronate in the treatment of Paget's disease of bone. A study of long-term results. Ann Intern Med 1977;87: 656-663.

40. Banerjee C, Hiebert SW, Stein JS, Lian JB, Stein GS. An AML-1 consensus sequence binds an osteoblastspecific complex and transcriptionally activates the osteocalcin gene. Proc Natl Acad Sci USA 1996; 93:4968-4973.

41. Liu W, Toyosawa S, Furuichi T, et al. Overexpression of Cbfa1 in osteoblasts inhibits osteoblast maturation and causes osteopenia with multiple fractures. $J$ Cell Biol 2001;155:157-166.

42. Ducy P, Desbois C, Boyce B, et al. Increased bone formation in osteocalcin-deficient mice. Nature 1996; 382:448-452.

43. Boskey AL, Gadaleta S, Gundberg C, Doty SB, Ducy $P$, Karsenty G. Fourier transform infrared microspectroscopic analysis of bone of osteocalcin-deficient mice provides insight into the function of osteocalcin. Bone 1998;23:187-196.

44. Nociti FH, Berry JE, Foster BL, et al. Cementum: A phosphate-sensitive tissue. J Dent Res 2002;81: 817-821.

45. Beck GR, Zerler B, Moran E. Phosphate is a specific signal for induction of osteopontin gene expression. Proc Natl Acad Sci USA 2000;97:8352-8357.

46. Johnson K, Goding J, van Etten D, et al. Linked deficiencies in extracellular PPi and osteopontin mediate pathologic calcification associated with defective PC-1 and ANK expression. J Bone Miner Res 2003; 18:994-1004.

47. Whyte MP. Hypophosphatasia and the role of alkaline phosphatase in skeletal mineralization. Endocr Rev 1994;15:439-461.

48. Boskey AL, Spevak L, Paschalis E, Doty SB, McKnee MD. Osteopontin deficiency increases mineral content and mineral crystallinity in mouse bone. Calcif Tissue Int 2002;71:145-154.

49. Felix R, Graham R, Russel RGG, Fleisch HA. The effect of several diphosphonates on acid phosphohydrolases and other lysosomal enzymes. Biochim Biophys Acta 1976;429:429-438.

50. Leyhausen G, Lorenz B, Zhu H, et al. Inorganic polyphosphate in human osteoblast-like cells. J Bone Miner Res 1998;13:803-812.

51. Tenorio D, Cruchley A, Hughes FJ. Immnocytochemical investigation of the rat cementoblast phenotype. $J$ Periodontal Res 1993;28:411-419.

52. Beertsen W, Niehof A, Everts V. Effects of 1-hydroxyethylidene-1,1-bisphosphonate (HEBP) on the formation of dentin and the periodontal attachment apparatus in the mouse. Am J Anat 1985;174:83-103.

53. Lekic P, Rubbino I, Krasnoshtein F, Cheifetz S, McCulloch CAG, Tenenbaum H. Bisphosphonate modulates proliferation and differentiation of rat periodontal ligament cells during wound healing. Anat Rec 1997; 247:329-340.

54. Wesselink PR, Beertsen W. Ankylosis of the mouse molar after systemic administration of 1 -hydroxyethylidene-1,1-bisphosphonate (HEBP). J Clin Periodontol 1994;21:465-471.

55. Hammarström L, Lindskog S. Factors regulating and modifying dental root resorption. Proc Finn Dent Soc 1992;88:115-123.

56. Lindskog S, Blomlöf L, Hammarström L. Repair of periodontal tissues in vivo and in vitro. J Clin Periodontol 1983;10:188-205.

57. Wesselink PR, Beertsen W. The influence of 1-hydroxyethylidene-1,1-bisphosphonate (HEBP) on dental root resorption in the mouse. Calcif Tissue Int 1989; 45:104-110.

Correspondence: Dr. Y.-H. P. Chun, Department of Periodontics/Prevention/Geriatrics, School of Dentistry, University of Michigan, 1011 N. University Ave., Ann Arbor, MI 48109. Fax: 734/936-0374; e-mail: ychun@umich.edu.

Accepted for publication March 28, 2005. 